\title{
INSTITUTIONALISING ETHICS IN ORGANISATIONS: THE ROLE OF MENTORING
}

\author{
X GOOSEN \\ LJ VAN VUUREN \\ Department of Human Resource Management \\ University of Johannesburg
}

\begin{abstract}
The phenomenon exists that organisations do not do much to ensure the institutionalisation of business ethics in general, and more specifically, to facilitate employees' ethical behaviour. The possibility that mentoring may be utilised as a vehicle to institutionalise corporate ethical practices is proposed as a possible solution to the aforementioned problem. By means of a qualitative study, interviews were conducted to determine whether mentoring is used to institutionalise business ethics, and if not, how it can be utilised. An integrated model of mentoring in the institutionalisation of business ethics was generated. It highlighted the compatibility of the mentoring- and institutionalisation of ethics processes. The implications are discussed.
\end{abstract}

\section{OPSOMMING}

Die verskynsel bestaan dat organisasies nie veel doen om te verseker dat besigheidsetiek in die algemeen geinstitutionaliseer word nie, en meer spesifiek, dat die etiese dimensie van werknemers gedrag nie plaasvind nie. Die moontlikheid dat mentorskap gebruik kan word as 'n instrument om korporatiewe etiese praktyke te institusionaliseer word voorgestel as 'n moontlike oplossing vir voorgenoemde problem. 'n Kwalitatiewe studie (onderhoude) is uitgevoer om te bepaal of mentorskap aangewend word om besigheidsetiek te institusionaliseer, en indien dit nie aangewend word nie, hoe dit wel kan geskied. 'n Geintegreerde model van mentorskap in die institusionalisering van besigheidsetiek is gegenereer om die versoenbaarheid van die mentorskap- en institusionalisering van besigheidsetiek- prosesse te beklemtoon. Die implikasies hiervan bespreek.

In recent years the question of business ethics has been discussed on many forums in South-Africa, as well as internationally. It seems therefore that this topic has drawn particular attention and the question is how did this apparent state of affairs develop?

Early speculations on the cause for organisational interest in business ethics indicated that the initial interest in business ethics was driven by a desire in the USA to avoid business scandals (De George, 1987). Although this was the initial cause of the interest in business ethics, it is no longer an adequate explanation for the current surge in organisational interest in business ethics. A number of other factors have since become prominent. The realisation of the cost of immorality to organisations on the one hand, and of the competitive advantage that ethical performance affords organisations on the other, may be the driving force behind this ongoing academic and organisational concern with business ethics (Rossouw \& Van Vuuren, 2003).

In order to investigate the impact of business ethics in organisations, it is necessary to firstly define the term ethics. "Ethics concerns itself with what is good or right in human interaction", (Rossouw, 2002, p. 3). In Rossouw's opinion ethics is centred on three basic concepts, namely the good, the self and the other. (Rossouw, 2002. p. 3).

An initial investigation into the term business ethics revealed a wide range of definitions. Rossouw (1994) defines business ethics as: "the specific application of this general principle (what is good or right for human beings) to business activities. To act morally within the business environment means ensuring that the consequences of business actions are not detrimental to others. Alternatively, to put it more positively: ensuring that business activities contribute towards personal well-being, the well-being of others and the societies who are influenced by these actions" (p. 2)

According to Rossouw and Van Vuuren (2003), there is sufficient empirical evidence that a stage has now been reached where

Requests for copies should be addressed to: M Coetzee, coetzm1@unisa.ac.za organisational interest in business ethics is moving beyond mere talk to overt organisational commitment to managing business ethics. In this new phase, the emphasis is no longer on the 'why' of business ethics, but rather on the 'how' of business ethics.

The business environment is extremely competitive and this threat to competitive advantage has become so important that organisations can no longer afford not to attend to business ethics. In this regard Van Vuuren (2002) states, "the strategic focus of organisations should consist of systematically embedding ethics in the corporate purpose and values, as well as in strategic planning" (p. 1). It is therefore apparent that business ethics has been elevated to a strategic level. To address business ethics only on the strategic level and in the boardrooms may, however, be a necessary but not sufficient intervention to ensure corporate ethical practices.

A business consists of various sub-systems. To implement ethics into one sub-system, e.g. sales, whilst ignoring other sub-systems such as manufacturing, will limit the impact of integrating ethical behaviour into the entire organisation, as this could create tension at the interface between the systems. It is therefore crucial that a 'holistic' systems approach should be followed. To achieve this, business ethics must be fused with the strategic plans, processes, management, communication, and culture of organisations. Various processes to institutionalise business ethics have been researched and established. Ethics committees, codes of ethics, selecting employees with integrity and ethics training are examples.

An ethical organisation is one that is managed in such a manner that the concepts of the good, the other and the self are in a harmonious relationship to each other, as to the process that organisations use to go about its economic activities (Rossouw \& Van Vuuren, 2004). Currently ethics in business seems to be based on an over-dependence and reliance on rules and regulations. The above may foster a compliance mentality that give ethics management endeavours a mechanistic and superficial feel.

It can be argued that, of course depending on the stage of development of the organisation and its particular activities, it 
may be more conducive for organisations to build cultures of value and integrity. The above refers to the integrity approach to institutionalising business ethics (Hartman, 2000). The creation of a culture of ethics does, however, not exclude any formal compliance initiatives. As formal compliance structures, e.g. corporate governance guidelines, increasingly become part of the local and international regulatory environment, organisations cannot afford to negate processes that ensure formal adherence. It is, however, crucial that organisations do not succumb to a minimalistic or legalistic tick-box approach to corporate ethics management.

Along with creating formal compliance structures, organisations need to nurture cultures that provide the ethical commitment necessary to turn formal compliance into effective, but voluntary and self-regulatory compliance. Ethics therefore is not merely a marketing tool, but needs to be made part of the everyday functioning of an organisation. It involves the interests of all stakeholders, internal and external, and it requires proactive ethics management. For the purpose of this study, the focus is specifically on the internal stakeholders of the organisation, i.e. the employees.

\section{Institutionalisation of business ethics on a systems level}

In the previous section, attention was given to ethics management on the strategic level. It is evident that the process of institutionalisation should not end at the strategic level. As stated in Rossouw and Van Vuuren (2004, p. 231), "designing and implementing ethics management systems are crucial to ensuring that the vision and strategy for ethics are made real throughout the organisation". Ethics management systems should be in place to provide for the introduction of ethics into various aspects of the organisation. Some of these systems are ethics communication systems (e.g. employee help-lines and newsletters), adopting integrity as a criterion in making selection decisions, utilising induction/orientation programmes to convey the ethics message, including ethical decision-making as a key performance area in performance management systems, build managerial ethics competence through training and development programmes, disciplinary procedures, as well as systems for monitoring and evaluating ethical performance and reporting on this to stakeholders.

\section{Institutionalisation of business ethics on an operational level}

Rossouw and Van Vuuren (2004, p. 242), explain that the "key to the operational level of institutionalising business ethics, is to ensure that ethical behaviour manifests itself in all jobs and interpersonal interactions." Bennis (1996) asserts that it is the job of every manager in the organisation to set the climate for ethical behaviour based on mutual respect. In an environment where interpersonal relations are built on mutual respect people will be more open to talk about ethics. Managers should be role models to other employees regarding ethical thought, decisionmaking and the actions they take.

Managers should obviously have a sufficient understanding of the processes and people that they have to manage. They are thus in a position to make a difference to organisational behaviour both at the individual and collective levels. This can be achieved through interventions where they apply their knowledge and utilise techniques and processes as well as material and symbolic resources to achieve the desired change in organisational behaviour. Moral behaviour in business is significantly influenced by the way in which managers use their managerial ability to influence moral behaviour in the organisational setting.

Mentoring is often used in organisations, not only to nurture and develop young talent, but to also give (especially) younger employees a sense of worth and unambiguous perceptions of what the organisation stands for and what the organisational culture ("the way we do things around here") is all about. The question can then be posed as to whether and to what extent mentoring can be utilised to convey the ethical component of the organisation's culture to employees. Once clarity is obtained on the above question, an approach can be suggested by which ethics could be institutionalised though mentoring.

\section{Mentoring}

Mentoring is defined by Cohen (1999) as a formally structured, non-reporting relationship used to enhance professional practice, personal knowledge and organisational development. Guest (2001) suggests that mentoring is about achieving personal growth and development that is effected by a confidential, one-to-one relationship in which an individual uses a more experienced, usually more senior person as a sounding board and for guidance. It is also a protected, nonjudgemental relationship, which facilitates a wide range of learning, experimentation and development. Mentoring can therefore facilitate professional development by promoting the capacity to cope with difficulties and develop new competencies at the personal, interpersonal, and institutional levels.

Hudson (1999) defines mentoring as "a supportive learning relationship between a caring individual who shares knowledge, experience and wisdom with another individual who is ready and willing to benefit from this exchange, to enrich their professional journey". This definition includes all the relevant components linked to mentoring, and will for the purpose of this paper be used as a working definition.

The above definitions indicate that the mentoring relationship is the foundation of mentoring. To understand this interactive relationship between mentors and their protégés, one first needs to investigate the meaning of the terms mentor and protégé, where after the dynamics of the relationship will be explored.

A mentor, according to the Oxford Dictionary, is a "trusted advisor". A mentor is a person with expertise in a variety of areas of interest, who is willing to share his or her wisdom. Young (2003). Bell, in (Harshman and Rudin, 2000), describes mentors as leaders who engage in deliberate actions aimed at promoting protégés' learning. Many people use the terms "advisor" and "mentor" interchangeably. However, a mentor is more than an advisor. Mentors guide protégés towards growth and development - they become trusted allies and guide protégés through their careers. According to Bell (1998), a mentor is someone who helps someone else learn something the learner would otherwise have learned less well, more slowly or not at all. A mentor should provide support and encouragement, assist protégés to learn from their mistakes, demonstrate personal integrity and provide protégés with meaningful information and direction. A protégé, as defined by Wickman \& Sjodin (1997, p. 2 ), "is the mentor's student, generally a younger person interested in learning all that the mentor has to offer". The protégé is someone the mentor regards highly enough to consider worthy of his or her time.

Mentoring relationships have proven to be key to a number of desirable outcomes in organisational life. The mentoring relationship is built over time and not a once-off occurrence. Mentoring is not an all-or-nothing relationship, nor is it static in nature. Some or all of the roles may be provided and they change since the purpose of the relationship is to enable the protégé to acquire new knowledge, skills and standards of competence. It is believed that mentoring relationships will be positively associated with performance, citizenship behaviours and individual intent. Mentoring involves a partnership where the point is to share and transfer knowledge, expertise and skills. It must be an intervention with the aim of building capacity to meet future leadership challenges and demands. According to Bell (1998), the role of the mentor is to stimulate the person being mentored, to facilitate the ability to reason 
and be self-aware, to enhance the objective analysis of situations and the application of insights to the workplace, to unlock an individual's own potential to maximise their performance and to influence another to achieve important goals or outcomes.

Mentoring relationships may vary between being highly informal relationships that develop naturally and are of unspecified duration on one hand, and relationships that form part of an organisational development programme that requires formally structured and non-voluntary relationships on the other hand. This paper focuses on the formally structured and non-voluntary type of mentoring relationship.

Three principles guide formalised mentoring in process and outcome. Firstly, mentoring allows individuals to build reciprocal relationships. Protégés who develop a firm foundation of appropriate social interactions are less at risk to develop social and behavioural difficulties. Guetzloe (1997) suggested that mentoring provides a framework for positive social networks and relationships. Secondly, mentoring relationships are important for individuals to engage in for purposes of completing tasks or achieving outcome goals Rockwell (1997). Thirdly, according to Miller and Townsel (1997), mentoring could be a tool to reinforce and build appropriate social values and norms from the business community's perspective. As part of the community's perspective, norms and values, such as honesty, sharing, and empathy can thus be modelled and reinforced through mentoring. It stands to reason then that mentoring could be used to entrench organisational ethical principles on a one-on-one basis throughout the organisation. Ethical behaviour might then be a logical outcome of formalised mentoring initiatives.

Mentoring is a powerful tool to convey information, expertise, beliefs and change of behaviour, either formally or informally, throughout all levels of the organisation. It is about a relationship between people in which skills, knowledge and attitudes are transferred from a trusted advisor to a protégé and incorporate the notion that senior members of the organisation will provide wisdom and guidance to junior members.

According to Kuo (2000), mentoring happens in many ways. Sometimes it occurs as a direct one-on-one relationship of involvement, and at other times it takes the form of a philosophy or methodology instilled in an organisation. Kuo states further that growing an organisation requires the philosophical approach to mentoring, but that this must be combined with practical "things to do" in order for the idea to take hold. Instilling a mentoring mindset within an organisation takes both time and perseverance.

Mentoring is thought to facilitate professional development by promoting the capacity to cope with difficulties and develop new competencies at the personal, interpersonal, and institutional levels. Having a mentor has been identified as a positive factor in retention, promotion, and advancement (Blackwell, 1989; Ezell \& Odewahn, 1980; Kram, 1985; Manoleas \& Carrillo, 1991; Zunz, 1991).

If mentoring is used by an organisation as a tool to institutionalise business ethics, business ethics as such must be a primary area of focus during mentorship. The mentor should thus receive training regarding personal and organisational values. Since behavioural change is the ultimate goal of the mentoring programme; mentors must know what motivates protégés and what they truly value. Mentors can work with protégés to discover, unearth and clarify their core values. Having discovered and clarified personal values, it is important that these be in harmony with those of the organisation. Peak performance is more likely to occur if there is a match between personal values and those of the organisation (Skiffington, 2002). Butler (2000) states that the foundation is set for future organisational success, when mentors convey the goals and values, of the organisation. Generic ethical organisational values could include dimensions of honesty, integrity, individual respect, fairness, consistency, transparency, etc. It is proposed that mentoring relationships may be ideal vehicles for the transfer of ethical principles such as these.

Furthermore, it is suggested that mentors could also play an active role in the following areas: creating an awareness of the importance of ethics in business; bestowing an ethical sensitivity on protégés; providing opportunities for protégés to acquire ethical reasoning and decision-making skills and being sensitive for the ethical consequences of such decisions; aligning protégés' behaviour to that required by the organisation's code of ethics; facilitating protégés' interpretation and application of the code of ethics; and equipping protégés with the courage to openly discuss ethics and to stand up for ethical stances adopted and decisions made.

From the above it is clear that mentoring seems to be a wellsuited vehicle to disseminate the ethics message in organisations and to facilitate ethical behaviour. In further answering the question phrased earlier, namely whether and to what extent mentoring can be utilised to convey the ethical component of the organisation's culture to employees, an empirical dimension is added to this study to investigate how ethics is or could be conveyed through formal mentoring processes. Thereafter a model depicting the dynamics between mentoring and ethics institutionalisation could be derived and presented.

\section{METHODOLOGY}

\section{Research design}

The crux of any research assignment is the statement of the problem: it is with the formulation of the research question that research can begin in that specific field. Contained within the stated problem, the area of study is demarcated thereby ensuring that the research remains focused and manageable. For the purpose of this study, the research question is to investigate the extent to which mentoring can be utilised as a vehicle to institutionalise corporate ethical practices. The research question guides the researcher in determining the aim of a study. The aim of this study is therefore to conduct an analysis of the extent to which mentoring can be utilised as a vehicle to institutionalise corporate ethical practices.

Once the research question and the sub-questions have been formulated and stated in clear and precise terminology, the next step in the research process requires that the objectives of the inquiry be stated. The research objectives can be stated as follows:

- To analyse the extent to which organisations make use of mentorship to institutionalise corporate ethical practices.

- To investigate whether mentoring is an appropriate tool to utilise in the institutionalisation of corporate ethical practices.

- To gain an understanding of how organisations institutionalise corporate ethical principles, using mentoring.

- To answer the question as to whether mentoring can be used as a means to institutionalise corporate ethical practices, and if so how.

Once the aim, the question and sub-questions, and the objectives of the research have been established, the researcher needs to design a vehicle (research design) to execute the above mentioned.

A research design has two basic purposes (Kerlinger, 1986:280). It is (i) the exposition of how the researcher plans to approach the finding of an answer to the research question that has been presented in the inquiry, and (ii) to control any variance that 
could occur. Thus, the term 'research design' can be understood as "a set of guidelines and instructions to be followed in addressing the research problem (question)" (Mouton, 1996:107). These guidelines and instructions are the presentation of the systematic account of how the research process was conducted. In planning the research design, determinants such as the collection and interpretation of the data, the paradigm, the context, time and labour is taken into consideration.

The next logical step in the research process is selecting a paradigm that would effectively and appropriately meet the requirements of the research as described in the research objectives. For the purpose of this study, the qualitative and quantitative paradigms were analysed from a naturalistic perspective.

Since the research question pertains to understanding and describing a particular phenomenon about which very little is known, the qualitative paradigm would appear to be most suitable for this inquiry. This inquiry is a process of discovery and learning Lofland (in Merriam, 1991) as the focus of the investigation is directed at the understanding of the situation from the participant's subjective perspective (Krefting, 1990; Mouton \& Marais, 1990, Field \& Morse 1985). Furthermore, the study involves a specific group of people who are asked questions particular to their experience of a mentoring programme Patton (in Merriam, 1991; Crabtree \& Miller, 1992) as they have specific knowledge pertaining to the phenomenon being investigated (Field \& Morse, 1985).

The qualitative approach allows the researcher the opportunity to explore meanings, variations and perceptual experiences of the phenomenon from a rich and in-depth perspective of the subjects as observed and recorded through their words, actions, behaviours and practices (Crabtree \& Miller 1992, Patton 1990). This method provides adequate information, appears to be cost effective and shows sensitivity towards the settings and resources (Marshall \& Rossman, 1995).

As the aim of this study involves the exploration and description of social and human phenomena, the researcher proceeds to analyse exploratory and descriptive methods of inquiry. The exploratory method of inquiry allows the researcher new ideas and possibilities without being led astray or influenced by predetermined ideas and existing hypotheses (Mouton \& Marais, 1990) pertaining to concepts of mentoring, business ethics and the institutionalising thereof. The exploratory method is thus used to gain insight and understanding into the social and human phenomena, for example ethical behaviour.

In descriptive research, the researcher aims at presenting the phenomenon under investigation as accurately as possible (Merriam, 1991; Dane, 1990) and at discovering new facts (Abdellah \& Levine, 1979). According to Schatzman and Strauss (in Wilson 1987), descriptive research is conducted in two ways namely, straight or analytical. In straight description, the analyst researcher may use categories or organisational schemes that are already existent in the literature pertaining to the inquiry. In analytical description, the inquirer attempts to create new categories when inspecting and coding the data. The new categories or classes will allow the researcher "to accurately and even insightfully characterise" the particular group under investigation (Wilson, 1987).

In this inquiry, the researcher applied the analytical description because the objective was to gain insight into and about ethics in mentoring relationships, of a particular group of people. Secondly, the inquirer presented a diverse account of findings, therefore having to create new categories to compliment the findings.

From the investigation the researcher came to the following conclusions that guided the researcher in the design and execution of this research. This research study is conducted from the naturalistic perspective and the qualitative paradigm appears to be most suitable. This research focuses on exploring and describing the phenomena in question, therefore exploratory and descriptive research is conducted.

Within the qualitative research paradigm a phenomenological approach was adopted. This method of data collection is most frequently used in exploratory and descriptive inquiries. Secondly, the phenomenological approach allows the researcher to study the subject's experiences as he/she has experienced them (Omery, 1983). The researcher envisaged the development of a picture of the Lebenswelt (Kvale, 1983) of the participants through inductive interviews, rather than to study cause-and-effect relationships of the phenomenon (Creswell 1994). In other words, the aim of the phenomenological approach, as in this study, is to try to understand the social and psychological phenomena from the subject's point of view (Huysamen, 1994). These direct experiences of the participants would thus be taken at face value (Cohen \& Manion, 1994; Field \& Morse, 1985). Given the nature of the approach adopted, the research could at best be described as exploratory and descriptive.

The research elements and findings are presented below, after which the findings are used to construct a theoretical model (from here on referred to as "The mentoring for ethics model" to explain how mentoring could be utilised to convey organisational ethical values.

\section{Participants}

The study was conducted at a Johannesburg Securities Exchange listed holding company. This company manages businesses in the electronics and low-voltage electrical engineering sectors supplying value-added products, systems and solutions to local and international growth markets. During 2003, this company introduced a mentoring programme, which took the form of a developmental process aimed at guiding less experienced employees by other, more experienced employees, or mentors.

Purposeful sampling implies that only information-rich cases are selected and studied in depth. Phenomenologists depend on indepth interviews to obtain their information, and it is therefore important that the participants who participate in the interviews are purposively selected (DePoy \& Gitlin, 1994). As Patton in (Leedy, 1997) contends, purposive sampling is applied as it helps to "increase the utility of information obtained from small samples". Only those subjects who had been exposed to mentorship relationships were approached to participate. Purposive, convenience sampling was therefore used to select the participants in this study. Members of the sample group had to have been involved in a mentoring programme for more than six months. Although it was a multi-cultural sample, all the interviews were conducted in English. Considerations such as gender, age and religion were not taken into account. Interviews were conducted with five mentors and their protégés (therefore 10 interviews in total).

\section{Procedure}

In order to collect and analyse data for this study, the researcher had to gain access to the site, select a sample for this study, choose a data collection method, and analyse and code the data gathered. Permission to conduct the study was obtained from the Human Resource Development (HRD) manager of the company where interviews were conducted. An appointment was made with the HRD manager to discuss the research to be conducted. Secondly, the researcher acquired convenient dates for the interviews to commence. Thereafter the first author took it upon herself to make contact, and arrange appropriate times and locations for the interviews to take place. The first contact between the respondents and researcher was on the day a particular interview was conducted. The respondents were briefed on the reason and format of the interview by means of 
a short introduction. They were given the opportunity to decline participation in the study. None of the respondents declined participation. Each respondent then signed a letter of consent. Once all these formalities were attended to, the interviews commenced.

\section{Data collection methods}

In naturalistic research, the inquirer "draws on and combines a variety of data collection strategies" (DePoy \& Gitlin, 1994:216). Examples of these include phenomenological interviews (Wolcott, 1994, p. 10), document analyses, consultations with experts, literature control in order to obtain a rich description, and a deep understanding of the phenomena being investigated. Through the combination of these datacollection strategies, the qualitative researcher describes the "viewpoint of the person under study" (Schmidt in Krefting, 1990 , p. 214). For the purpose of this study phenomenological interviews, literature review and peer debriefing were used as data collection methods.

\section{Literature review}

The literature review consists of information published and unpublished, which relates closely to the area of inquiry. Both primary and secondary sources will be included in the literature review. The literature control was undertaken for the following reasons: Firstly, it is very useful to conduct a literature review prior to the investigation because it enabled the researchers to know what research has been conducted relating to the issue under investigation (Morse in Holloway \& Wheeler, 1996). Secondly, to explore existing knowledge and practices, and thirdly, to ensure that effective questions were developed for the interviews.

\section{Phenomenological interviews}

There are various methods of data collection in naturalistic inquiries: participant observation, interviews, the studying of materials prepared by others relating to the field of inquiry (Wolcott, 1994), researcher-designed instruments, as well as content analysis of human artefacts (LeCompte \& Preissle, 1993). The utilisation of the interview, and more specifically, the phenomenological interview, was selected for this study.

Ackroyd and Hughes (in Schurink, 1988, p. 136) describe phenomenological interviews as the most "important data collection instrument in the social sciences ..." They point out that phenomenological interviews are repeatedly used in exploratory and descriptive studies.

This type of interview allows the researcher the opportunity to try to gain direct access "to what is inside a person's head." Tuckman in (Cohen \& Manion, 1994, p. 273). It also affords the researcher and the respondent the opportunity to move "back and forth in time, reconstruct the past, interpret the present and predict the future" (Lincoln \& Guba in Erlandson, Harris and associates, 1993, p. 85). This type of interview could therefore be a powerful method to gain an understanding of the phenomenon being investigated from a participant's perspective (Denzin \& Lincoln, 1994). Furthermore, participants were allowed to express themselves in their own natural language and at the same time express themselves from within their own unique paradigms (Guba \& Lincoln, 1988), without any reservation and/or interference from the inquirers. The phenomenological interviews were therefore applied as "a conversation with a purpose" (Dexter, 1970, p. 136). The researchers took it upon themselves to guide and direct the inquiry towards the specific topic of research as recommended by Field and Morse (1985).

The interviews were of a semi-structured nature. Such an interview format is more flexible and open. The semi-structured format also seems to be of value when the subjects included in the inquiry consist of a purposively selected group who are familiar with the research topic. This format allows the inquirer to explore more fully the opinions and behaviours of respondents and for "more and varied detail" (Dane, 1990, p. 129 ) in the accounts of the life-world of the subjects (Huysamen, 1994, p. 174).

Although the research problem governs the questions asked, the researcher decides on the content, sequence and wording. The format allowed the researchers the opportunity to pose a few predetermined questions, whilst simultaneously allowing for a considerable amount of "flexibility concerning follow-up questions", as suggested by Merton, Fiske and Kendell in Dane (1990, p. 129). This, in turn, gave the researchers the opportunity to clarify any misunderstandings that could arise during the questioning. Furthermore, this approach created the opportunity to take each respondent through the same set of questions in a systematic fashion.

Several open-ended questions were formulated that could guide participants on the topic being investigated, in order to learn about their beliefs, attitudes, reported behaviours, or prevalent experiences. Two sets of interviews were conducted. Five interviews were conducted with mentors, with a set of questions, and five interviews were conducted with their protégés, with their (slightly different) set of questions. The questions asked were directed towards the collection of information relating to the topic of investigation.

Researcher should be aware that factors such as speech, status, dress, grooming, age, race and frame of mind can affect and influence responses of the participants (Krathwohl, 1993, p. 198). Special attention was paid to the aforementioned and the necessary precautions were taken to attempt to counteract any negativity. The interviewers were aware that their perspectives and biases may affect the outcome of the interview. Therefore, when interviewing commenced, the researchers attempted to suspend all forms of biases.

\section{Data analysis}

The purpose of data analysis is to transform the acquired data obtained from the phenomenological interviews into rich descriptions of the findings. An analysis involves not only the translation of the information but also the interpretation thereof. Data analysis is the means by which a researcher brings "order, structure and meaning to the mass of collected data" (Marshall \& Rossman, 1995, p. 111). In the qualitative research approach, the analysis of data is an interactive process, and not linear (Crabtree \& Miller, 1992, p. 71). Researchers make use of one of the methods of analysis as described by Abdellah and Levine (1979, p. 357); Merriam (1991, pp. 158-159) and Patton (1990, p. 384), namely the computer analysis or the hand method. The analysis consists mainly of words. In this study, the analysed results contain words and/or phrases obtained from the raw data. These words and/or phrases are arranged into themes, categories and subcategories to illustrate and substantiate the findings of the inquiry.

Since data analysis is an eclectic process (Tesch, 1990 in Cresswell 1994, p. 53), this inquiry adopted transcriptbased analysis methods. A transcript-based analysis infers that data analysis can only begin once the audio taped recordings have been verbatimly transcribed. The verbatim transcriptions of the recordings forms an essential part of the data analysis, as the researcher tried to incorporate and include all meanings and nuances of the subjects. Verbatim transcriptions of the interviews provide rich forms of data.

The entire verbatimly-transcribed descriptions of the questions presented to the respondents were analysed to obtain a sense of whole. The interviews were read again with the purpose of identifying the major units of analysis. All categories and 
subcategories that were not considered meaningful were eliminated, while the remaining categories were counted and assigned to various themes.

The researcher analysed the transcribed interviews using marginal notes to capture frequently recurring words, ideas and phrases relevant to the study. Field and Morse (1985, p. 137) argue that the identification of such elements aids the identification and analysis of the underlying patterns in the data. This in turn helps develop categories, which will elucidate and fit the acquired data (Bryman, 1995). Once all the data from the interviews were collected and transcribed, the next stage entailed the coding. The verbatim transcripts were read through several times in order to try to obtain a sense of the whole. During the above process, the researcher once again used notes, comments and queries in the margins.

\section{RESULTS}

Primarily through the process of data analysis, as suggested by Kerlinger (1986), the captured data from the 10 interviews was analysed and subsequently interpreted. Key-phrases-in-text were utilised as the units of analysis and categories, themes and subthemes were identified on the basis of similarity and dissimilarity. The process was initiated without any preconceived ideas about categories, themes or sub-themes and a grounded theory approach was followed throughout.

Data generally appeared to cluster within two main categories: (i) mentoring and (ii) ethics in mentoring. Themes and subthemes emerged within each of these categories. The number of responses did not determine whether a category, theme or subtheme would be included; inclusion depended solely upon the relevance of the response to the study. It also has to be made clear that categories, themes and sub-themes should not be seen as exclusive: a degree of overlap existed in most instances and a holistic (Gestalt) approach was followed in the final interpretation to illuminate important links and relationships between different concepts. For the sake of clarity, the two categories will be discussed separately. Thereafter an integrated view will be presented.

Within the first category (mentoring) three themes were identified:

- Formal mentoring programme: (Five sub-themes were identified)

A Sub-theme 1: Content of the formal programme

B Sub-theme 2: Participants' experience of the formal programme

C Sub-theme 3: Pairing of participants

D Sub-theme 4: Goal for the formal mentoring programme

E Sub-theme 5: Training of mentors

Three important aspects were noticed from the responses:

(i) It was particularly apparent that the pairing process followed a rather coincidental path. This is in contrast to the conventional wisdom reported in the literature review that suggested organisations consider established informal mentoring relationships when pairing candidates for a mentoring programme. It was argued that the dynamics of 'forced pairing' relationships might be incompatible, and may lead to mentoring being unsuccessful. It is possible for informal mentoring relationships to exist before entering a formal relationship.

(ii) It was also noticeable that even if the organisation had a goal for the formal mentoring programme, neither mentors nor protégés were well aware of it.

(iii) Another important aspect of the formal mentoring programme that was not addressed by participants was any form of evaluation of the mentoring programme. The literature overview argued strongly for some form of evaluation (formative and summative) of such an intervention. Certain outcomes need to be set for such a programme and a measuring tool should be used to determine whether these outcomes were met.

In order to present an integrated model of mentoring for ethics (Figure 2), responses regarding a formal mentoring programme was re-phrased and summarised under the following headings (Table 1), to cover all of the important aspects believed to be relevant.

\section{TABLE 1}

ASPECTS RELATED TO A FORMAL MENTORING PROGRAMME
- Purpose of a formal mentoring programme
- Outcomes of a formal mentoring programme
- Pairing of candidates in a formal mentoring programme
- Content of a formal mentoring programme (e.g. a module related to codes of ethics)
- Evaluation of a formal mentoring programme
- Benefits of a formal mentoring programme

- Mentoring relationships: (Four sub-themes were identified)

A Sub-theme 1: Pre-requisites and characteristics of mentoring relationships

B Sub-theme 2: Relationship development

C Sub-theme 3: Mentors role in mentoring relationship

D Sub-theme 4: Protégés experience of mentoring relationship

The mentoring relationship was regarded by most as the 'golden thread' that runs through the mentorship process. The implied implication was clearly that, without a mentoring relationship, mentoring could not take place. It also seemed that effective two-way communication was regarded as a prerequisite for a mentoring relationship to be successful. In this study, most participants indicated that their mentors followed an open-door policy, and that they have informal discussions on a regular basis. What distinguishes these informal discussions from the training in the formal mentoring programme is that 'theory' is applied in the first whereas informal mentors tend to use real life situations to assist them in solving problems and making decisions.

It was further noted that the forming of a mentoring relationship is a natural process. It is a process where a senior person in an organisation gives advice, assist and model jobrelated and personal 'know-how' to a junior employee. If a protégé chooses a mentor in an informal mentoring relationship, it would be someone that the protégé looks up to, feels comfortable interacting with, is willing to assist, and finds trustworthy. The mentor need not necessarily be the protégé's direct supervisor, but can be any person in the organisation, depending on the aim of the organisation's mentoring programme.

These responses from the participants were mostly in line with the ideas from the literature review reported earlier which suggests that the mentor should be a good example with regard to interpersonal relations, decisionmaking and conflict management. It was also argued that these informal relationships could possibly continue when a formal mentoring relationship is established and that organisations should consider when the pairing of mentors and protégés takes place. An alternative scenario might be when a new mentor is assigned to a protégé. Mentors and protégés interviewed for this study were also 
of the opinion that a mentor would have a better understanding of the role if he/she had been a protégé in a mentoring relationship.

Because the formal mentoring programme continues for approximately one year, participants felt that they were 'forced' to persist in the mentoring relationship for at least that period of time. Participants indicated that they often initially did not feel comfortable within the relationship, but that the relationship grew over time.

To assist in the development of the Mentoring for ethics model later in the discussion, the following headings were considered to cover all that needs to be taken into consideration when considering effective mentoring relationships (Table 2).

TABle 2

ASPECTS RELATED TO MENTORING RELATIONSHIPS
- Pairing of mentor and protégé
- Process of relationship building
- Prerequisites for effective mentoring relationships
- Characteristics of mentor for a successful mentoring relationship
- Characteristics of protégé for a successful mentoring relationship.

- Benefits of mentoring: (Three sub-themes were identified) A Sub-theme 1: Benefits of mentoring for the organisation

B Sub-theme 2: Benefits of mentoring for the mentor

C Sub-theme 3: Benefits of mentoring for the protégé

From the responses one has to assume that either very little thought had gone into the benefits an organisation could derive from mentoring, or the respondents had limited knowledge in this regard.

Although mentoring focuses on developing protégés, it appears as if mentors also benefit from mentoring in various ways. Mentors felt that if they mentor a protégé effectively, their own workload can reduce meaningfully. Protégés do not make as many mistakes, and they are better at problem-solving and decision-making. Therefore, mentors have a vested interest in the success of their protégés. Mentoring gives mentors an added benefit of feeling good about themselves, as they play an integral role in the holistic development of their protégé. Most of the mentors interviewed for this study, indicated that they feel good because of what they contribute to the lives of their protégés. Lastly, mentoring contributes to the mentor's learning curve, as it is not only the protégé that has developed, but also the mentor.

From the interviews, it was clear that protégés benefit most from mentoring. The protégé is holistically developed. This means that the protégé does not only acquire jobrelated skills, but gains skills, knowledge and expertise in his/her personal and work life. Thus, personal and career growth takes place. The protégé is developed by means of a transfer of knowledge and skills from the mentor to the protégé. The mentor takes personal interest in the protégé, and provides him/her with advice and assistance. It was made clear that mentoring is a positive experience for protégés that leads to increased confidence, increased problem-solving ability, increased self-esteem, increased self-worth and independence. Mentors assist and guide protégés in developing their decision-making and problemsolving capabilities.

As was done in earlier sections of the discussion the following headings were considered relevant for inclusion in a final explanatory model to cover all aspects related to the benefits of mentoring. (Table 3)
TABLE 3

ASPECTS RELATED TO THE BENEFITS OF MENTORING

\begin{tabular}{|c|c|}
\hline For the organisation: & $\begin{array}{l}\text { - } \quad \text { Competent staff } \\
\text { - } \quad \text { Efficient staff } \\
\text { - Knowledgeable staff }\end{array}$ \\
\hline For the mentors: & $\begin{array}{l}\text { - Adds to mentors learning curve } \\
\text { - Reduces mentors problem-solving lead } \\
\text { - Vested interest in protégés success } \\
\text { - Added benefit of feeling good about } \\
\text { him/herself }\end{array}$ \\
\hline For the Protégés: & $\begin{array}{l}\text { - Mentor takes personal interest } \\
\text { - } \text { Advice, assistance } \\
\text { - } \text { Transfer of knowledge and skills } \\
\text { - Leads to increased confidence- Increased self- } \\
\text { - } \text { esteem, self-worth } \\
\text { - } \text { - Pain experience, independence } \\
\text { - Increased problem-solving ability }\end{array}$ \\
\hline
\end{tabular}

- Within the second category (Ethics in mentoring) four themes were identified:

\section{A Concept of ethics}

From the interviews it was clear that the perception of the term ethics is not uniform. Most participants though were of the opinion that ethics is "what's right and wrong." One would have expected that all the participants, because they are employees of the same holding company, should have been informed of the same set of ethical principles applicable throughout of the company. Although all employees were, to some extent, aware of the existence and importance of business ethics, most were of the opinion that unethical behaviour is present in all organisations. Some participants were of the opinion that it is basically impossible to change a person's personal value system, whereas other participants felt strongly about the fact that it is of utmost importance to change employees' personal value systems to ensure a change in ethical behaviour within the organisation itself.

B Codes of ethics and organisational transfer

1. Sub-theme 1: Code of ethics

2. Sub-theme 2: Organisational transfer

For ethical transfer to take place, it was generally believed that top management must be committed and seen to be 'living' the organisation's code of ethics. The participants were further of the opinion that an ethical top management does not necessarily ensure an ethical workforce, the reason being that there are often somewhat impersonal relationships between top management and staff and limited communication between members from the different organisational levels. For the effective transfer of business ethics to take place, well-established one-on-one relationships need to exist between supervisors and employees (or mentors and protégés). The conviction was expressed that appropriate ethical behaviour should be part of the everyday life of all employees. In the specific organisation studied, it was believed that a zero tolerance stance towards unethical behaviour was maintained despite the fact that the consequences of unethical behaviour might not have been formally communicated to employees.

It was generally argued that the top management of this organisation does not manage ethics at all. Top management were expected to support and commit to the process if success were to be expected. The formulated code of ethics needed to be communicated to all employees. From the above discussion, it should be clear that the organisational context creates the setting for ethical transfer to take place in an organisation. Figure 1 below reflects this notion. 


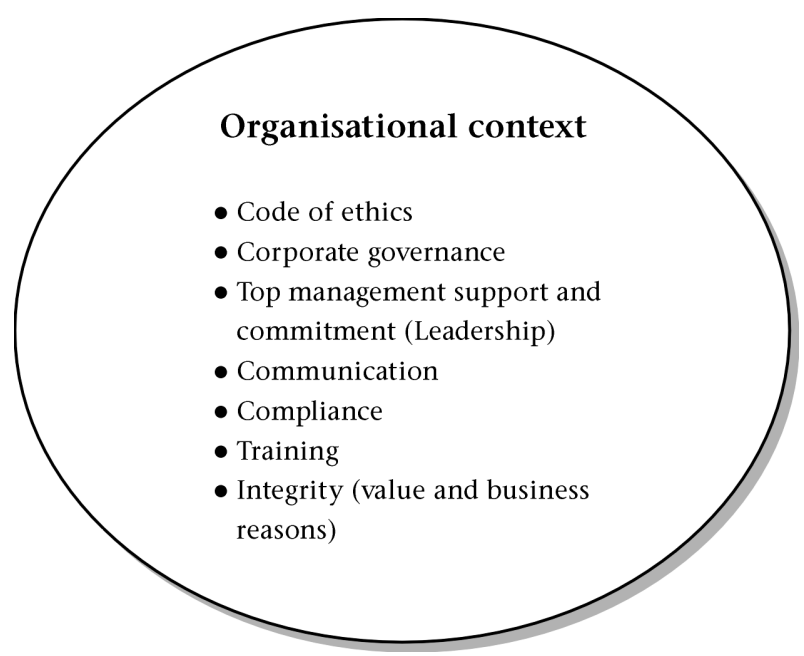

Figure 1: Context for organisational transfer of code of ethics

C Ethics training in the formal mentoring programme

Most participants of this study were of the opinion that formal ethics training of employees needs to take place. During training, the employees should be informed of what the organisation stands for in terms of expected (and rejected) ethical (unethical) behaviour. Ethics training could address the organisation's code of ethics as well as universal concepts like honesty, integrity and interpersonal conduct. From the interviews conducted it was evident that formal ethics training alone does not ensure a corporate culture of 'living' the code of ethics. It is therefore imperative that the organisation implements processes on the operational level to ensure the institutionalisation of ethical behaviour.

Participants of this study were of the opinion that the formal mentoring programme could serve as a platform for ethics training. In this regard, mentors should be trained on the code of ethics, to enable them to transfer ethics knowledge and skills to their protégés. Apart from the theoretical training on ethics, the mentoring relationship makes it possible for mentors to use everyday examples, to illustrate appropriate and inappropriate behaviour.

From the interviews conducted, it was clear that the organisation does not formally make use of mentoring to transfer ethical principles. Little attention is given to ethics in the formal mentoring programme. The programme consists of various modules, and in only one of the modules, ('knowing yourself') values are addressed to some extent. This module makes it easier to talk about ethics as the mentoring relationship develops. The mentors interviewed, were of the opinion that the formal mentoring programme would be the ideal platform to address ethical issues (in particular the code of ethics). Certain concepts needed to be covered during ethics training. These concepts are summarised below (Table 4).

TABLE 4

ASPECTS RELATED TO ETHICS TRAINING IN THE FORMAL MENTORING PROGRAMME

- Formal ethics training in terms of code of ethics

- Formal ethics training in terms of organisational values

- Formal ethics training for mentors and protégés

- Training with regard to code of ethics, organisational values, organisational culture and interpersonal conduct

- Training with regard to excepted and rejected ethical behaviour

- Should address consequences of unethical behaviour
D Ethics in the mentoring relationship

1. Sub-theme 1: The ethics within the mentoring relationship

2. Sub-theme 2: The organisational ethics transferred by means of mentoring relationship

Participants confirmed that for ethics to be transferred, a solid mentoring relationship should have been established. Two factors were identified namely, (i) the ethics within the mentoring relationship and then (ii) the organisational ethics transferred by means of mentoring.

In terms of the first factor (ethical relationship) participants indicated that a mentoring relationship should be built on ethical principles for them (protégés) to feel comfortable to talk about ethics. Thus for mentoring to be effective, and ethics to be conveyed, an ethical mentoring relationship needs to exist. The relationship should be built on ethical principles like trust, honesty and integrity. Protégés are of the opinion that they need to see their mentors as ethical people for the mentoring relationship to be effective. The mentor should therefore be an ethical role model and example to his/her protégé.

Related to the second factor, participants indicated that mentors need to build a relationship with protégés to be able to address (talk about) ethics. It appears that the stronger the mentoring relationship, the easier it becomes to talk about ethics. Very little talk about ethics can take place if a one-on-one relationship does not exist. According to participants, this one-on-one relationship can create a better person (protégé) that believes in organisational ethics. A shared mindset regarding the organisation's ethics is a prerequisite for effective ethics transfer within the mentoring relationship. If a mentoring relationship exists, talking about ethics comes naturally and is entwined in all aspects of that relationship. A holistic approach to ethics should be followed, and therefore ethics is not just an add-on topic that needs to be addressed. Mentors lead by example and therefore act as role models. Protégés need to see their mentors as ethical persons, for ethics to be conveyed. If a problem arises, the mentor addresses it in terms of ethical behaviour, and the consequences thereof. The mentor assists his protégé in work-related as well as personal ethical dilemmas.

The organisation where interviews were conducted does not expect of mentors to formally discuss organisational ethics, however mentors do discuss ethics informally. Mentors agreed that it should be done and that it is important. Ethics as a formal topic is not discussed, but appropriate and inappropriate behaviour is discussed on an informal basis. If a problem of inappropriate behaviour occurs, the mentoring relationship is used as a platform to discuss ethics. Informal ethics talk is important but mentors and protégés need a code of ethics as a guideline for these discussions.

Ethics talk therefore mainly takes place within the mentoring relationship, although the researcher is of the opinion that training and discussions on organisational ethics should also be addressed within the formal mentoring programme. For the transfer of ethics to take place, the mentoring relationship needs to meet certain requirements. These requirements are summarised below (Table 5).

The above sections dealt with mentoring and ethics on an individual basis, but to serve the purpose of this study, it is of importance to integrate these two processes. From the information identified during the analysis of the interviews conducted (Tables $1-5$ and Figure 1) and related literature study, the following model (see Figure 2) is proposed to aid understanding of the usefulness of mentoring as an intervention to institutionalise business ethics. 
TABLe 5

\section{ASPECTS RELATED TO THE ETHICS IN THE MENTORING RELATIONSHIP}

- Ethical mentoring relationship

- Informal ethics talk and share ethical experiences

- Create ethical awareness

- Transfer ethical principles

- Discuss consequences of unethical behaviour

- Build a one-on-one relationship

- Follow holistic approach to ethics

- Ethical relationship makes ethics talk easier

- Mentor is an ethical role model

- Transfer of organisational ethical principles in everyday working life

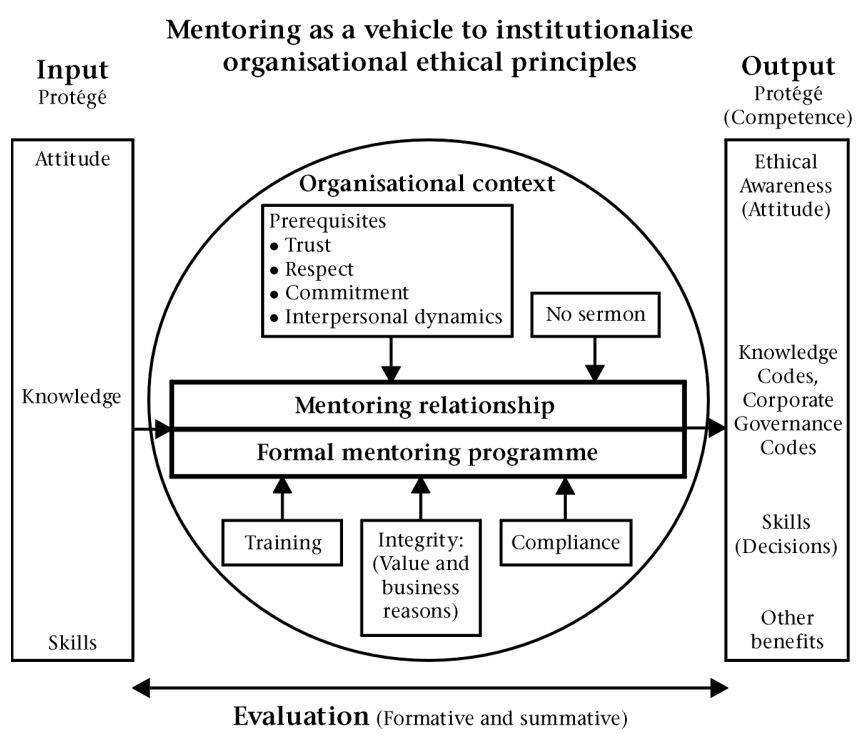

Insert Figure 2. Development of the mentoring for ethics model

The model consists of an integration of Tables $1-5$ and Figure 1. However, it was believed that certain aspects of this approach were still lacking and therefore information from the literature study was used to complete the model. The model was built on the systems approach. On the input side is the protégé with his/her knowledge, skills and attitudes regarding organisational ethical principles when entering the mentoring relationship. As a result of exposure to the formal mentoring process (programme and relationship) the expected output is a protégé with (i) an attitude which portrays ethical awareness (ii) skills which include a thorough knowledge of organisational ethics (organisations' codes of ethics) and principles as set out in the corporate governance codes and guidelines (e.g. the King II report (see IoD, 2002)) (iii) skills that will make him/her competent to take decisions, solve problems and interact within the expected ethical standards of that particular organisation.

The formal mentoring programme normally takes place on a monthly basis and continues for a period. (In the case of the organisation studied the time period was one year). The core of the mentoring process is the mentoring relationship that has developed. Mentors should be well chosen in terms of their suitability to convey ethical messages. Mentors and protégés should also be compatible in terms of personality, thus enabling ethics talk to take place within the mentoring relationship. Organisations need to ensure that the organisational context is conducive to the development of such a relationship as well as for business ethics to be institutionalised. To create such an environment organisations need to have a code of ethics, a plan to institutionalise business ethics in all levels of the organisation and a culture of integrity. The above all takes place within the organisational context.

The formal process as well as the mentoring relationship needs to be monitored and evaluated throughout the mentoring process. This would give the person responsible for ethics management in the organisation an indication of the extent to which the mentoring process enhances the institutionalisation of ethics within that particular organisation. It would furthermore indicate possible improvements that organisations can make in terms of the mentoring process. (E.g. the pairing of participants, the training of mentors and protégés and the content of the formal mentoring programme).

The outcome of mentoring as discussed previously in this section would largely be determined by the mentoring intervention. If this intervention is well planned, implemented and evaluated, it can lead to numerous benefits to the organisation, mentors and protégés, including the opportunity to make protégés aware of codes of ethics, ethics-related issues in the organisation and to provide them with skills to deal with such issues.

\section{RECOMMENDATIONS}

\section{Recommendations for organisations implementing} mentoring programmes

The results of this study clearly indicate that mentoring can play a significant role in the institutionalisation of organisational ethics. A proviso is, however, that the organisation actually has a code of ethics that serves as an ethical guideline to all employees. Mentoring should be a well-planned and implemented process. Mentors should be formally trained on the company's code of ethics as well as the ethical requirements of a mentoring relationship. The pairing of mentoring participants is of utmost importance. Ethical transfer will take place if the protégé perceives his/her mentor as ethical. The mentoring process consists of the formal mentoring programme and the more informal mentoring relationship. During the mentoring programme formal ethics training will create and awareness of the organisation's code of ethics, as well as the ethical expectations they have of their employees. On the other hand, a one-on-one mentoring relationship that develops between a protégé and an ethical mentor over time, would pave the way for the transfer of ethical principles to occur.

Introducing a mentoring programme in an organisation should be a process that is well thought through and well-planned. Mentoring offers numerous benefits to organisations of all sizes, if it is correctly implemented and followed through. Mentoring is addressed in literature, which should enable organisations to plan such an intervention effectively. In terms of ethics, the literature is clear on the importance and necessity thereof. Although the institutionalisation of ethics in organisations is a fairly new focus of attention in organisations, it has been investigated in some detail. From the literature as well as the empirical study conducted, it is evident that these two interventions implemented by organisations to improve their effectiveness, are typically not integrated.

The objective of this study was to highlight the role of mentoring in institutionalising business ethics. This intervention takes place on the operational level of the institutionalisation process. Organisations that already implement mentoring programmes may very well consider using mentoring for creating an ethical awareness, educating employees on ethics in general as well as the organisation's ethical code, and through the mentoring relationship ensure that employees incorporate business ethics in their everyday work life. 
Recommendations for designers of mentoring programmes Designers of mentoring programmes can now possibly design these programmes not only as interventions for career advancement, but also to assist organisations in the institutionalisation of their business ethics. In the planning process, certain elements of the ethical transfer need to be built in. The formal mentoring programme should make provision for the training of mentors on the organisation's code of ethics, how ethical transfer takes place, and what their role is in this transfer process. Ethics is not just another add-on module in the mentoring programme, but should be integrated in all aspects of mentoring. Protégés need to be trained to create an awareness of ethics as well as to familiarise protégés with the content of the code of ethics.

An important component of the mentoring process is the mentoring relationship. This is where the institutionalisation takes place. If designers of mentoring programmes are involved in the pairing of mentors and protégés, attention should be given, as the choice of mentoring pair is the basis for the mentoring relationship. Designers should lastly incorporate evaluation interventions when planning a mentoring programme to ensure that ethical transfer takes place.

\section{Recommendations for tertiary institutions involved in management training}

Given the significance of business ethics in modern organisations, organisational ethics should ideally be part of every student's syllabus when studying towards a managerial qualification. Subject content would have to cover ethics and the institutionalisation thereof extensively. On the operational level, mentoring could then be added as a possible method to assist organisations in ensuring effective institutionalisation. The integrated model as proposed earlier could possibly facilitate understanding of the role mentoring can play in the institutionalisation process.

\section{CONCLUSION}

In conclusion it is appropriate to make certain recommendations for further research: (i) the further exploration of the extent to which the descriptive and interpretative material yielded herein could be applicable to mentorship relationships in organisations generally, (ii) an evaluation of the nature of implementation and the impact of mentoring as an organisational ethics intervention, (iii) the development of an integrated curriculum (at graduate and post-graduate levels) in the training of managers with regard to the role of mentoring in the institutionalisation of business ethics.

In the area of research, limitations necessarily apply. In the case of this specific research, the following restrictions were noted. This study focused on qualitative research only. Triangulation, i.e. qualitative and quantitative research, might have been an alternative. The interviews conducted were done with a specific component. Ideally, a random selection of employees who had undergone mentoring, in a variety of organisational sectors, could have been interviewed. Another option could have been to conduct a comparative analysis pertaining the impact of mentoring on organisational ethical behaviour. Limited information was gained about the true dynamics of a mentoring relationship in terms of ethics, and in retrospect could have received more attention in this study. A more comprehensive analysis could be considered for further research.

As depicted in this study, business ethics has to become an integral part of any organisation. It should be a planned, participative and well-communicated process that takes place from strategising right through to the operational level of any given organisation. On an operational level, business ethics need to become part of each employees working life to ensure institutionalisation.
From this study, it became apparent that mentoring could be used effectively to enhance the institutionalisation of business ethics on the operational level. Mentoring is not a new concept and much research has been conducted on this topic. The reasons for organisations implementing mentoring in their organisations might differ, but most organisations find the mentoring process - if well-planned, implemented and followed through - to be beneficial. Well-documented research on the process, content, advantages and disadvantages are available to prospective researchers. The fact remains that depending on the organisation's goal for introducing a mentoring programme, each mentoring programme needs to be tailor-made for that specific organisation and participants. It is thus possible for organisations to make use of mentoring as an intervention and to ensure that their employees are aware of ethics. It creates a platform for ethics talk to take place. An ethical mentoring relationship paves the way for senior staff (mentors) to transfer ethical principles, as well as being role models in this regard. This type of transfer takes place formally and informally. As the respondents of this study commented, more effective ethical transfer takes place in the setting of a one-on-one relationship with an ethical trusted advisor (mentor).

What remains to be seen is whether organisations realise the true value of institutionalising business ethics. Only when top management become committed and ethical themselves, can it be expected of their employees to follow suite. Hopefully this study may add to the intervention possibilities that are at the disposal of those committed to and responsible for ethics management in organisations.

\section{REFERENCES}

Abdellah, F.G. \& Levine, E. (1979). Better patient care. A thorough nursing research. New York: Macmillan.

Bell, C. R. (1998). Managers as mentors: Building partnerships for learning. San Francisco: Berrett-Koehler.

Bennis, W.G. (1996). Beyond leadership: Balancing economics, ethics and ecology (2nd ed.). New York: Blackwell.

Blackwell, J. (1989). Mentoring: An action strategy for increasing minority faculty. Academe, 74 (5), 7-14

Bryman, A. (1995). Quantity and quality in social research. London: Routledge.

Butler, R. (2000). The ideal work environment. Armed Forces Comptroller, 45 (I3), 49-61.

Cohen, N. (1999). Effective mentoring. Amherst, MA: HRD Press.

Cohen, L. \& Manion, L. (1994). Research methods in education (4th ed.). London: Routledge.

Crabtree, B.F. \& Miller, W.L. (1992). Doing qualitative research. Beverly Hills, CA: Sage.

Creswell, J.W. (1994). Research design. Qualitative and quantitative approaches. Beverly Hills, CA: Sage.

Dane, F.C. (1990). Research methods. Monterey, CA: Brooks/Cole.

De George, R.T. (1987). The status of business ethics: Past and future. Journal of Business Ethics, (6), 201-211.

Denzin, N.K. \& Lincoln, Y.S. (1994). Handbook of qualitative research. Beverly Hills, CA: Sage.

DePoy, E. \& Gitlin, L.N. (1994). Introduction to research. St. Louis: Mosby.

Dexter, L.A. (1970). Elite and specialised interviewing. Evanston: Northwestern University Press.

Erlandson, D.A.; Harris, E.L.; Skipper, B.L. \& Allen, S.D. (1993). Doing naturalistic inquiry. A guide to methods. Beverly Hills CA: Sage.

Ezell, H. \& Odewahn, C. (1980). An empirical inquiry of variables impacting women in public service organisations. Administration in Social Work, 4 (4), 45-60.

Field, P.A. \& Morse, J.M. (1985). Nursing research - The application of qualitative approaches. London: Chapman and Hall.

Guba, E.G. \& Lincoln, Y.S. (1988). Effective evaluation. San Francisco: Jossey - Bass. 
Guest, A.B. (2001). Organisational mentoring. The Coaching \& Mentoring Network.

Guetzloe, A. (1997). The power of positive relationships: mentoring programs in the school and community. Preventing School Failure, 41 (3), 100-104.

Harshman, E.M. \& Rudin, J.P. (2000). Corporate mentoring programs: Legal landmines. Journal of Employment Discrimination Law, 1 (2), 135-142.

Holloway, I. \& Wheeler, S. (1996). Qualitative research for nurses. Oxford: Blackwell Sciences.

Hudson, F. M. (1999). The handbook of coaching. San Francisco: Jossey-Bass.

Huysamen, G.K. (1994). Methodology for the social and behavioural sciences. Halfway House: Thomson.

IoD (2001). King Report on Corporate Governance for South Africa. Johannesburg: Institute of Directors (IoD).

Kerlinger, F.N. (1986). Foundations of behavioral research (3 ${ }^{\text {rd }}$ ed.). Chicago: Holt, Rinehart and Winston.

Kram, K.E. (1985). Mentoring at work: Developmental relationships in organisational life. Glenview, Illinois: Scott, Foresman.

Krathwohl, D.R. (1993). Methods of educational and social science research - an integrated approach. New York: Longman.

Krefting, L. (1990). Rigor in qualitative research: The assessment of trustworthiness. The American Journal of Occupational Therapy. 45 (3), 214-222.

Kuo, K. (2000). The power of mentoring. Educause Review. 35 (2), 8-11.

Kvale, S. (1983). The qualitative research interview: A phenomenological and a hermeneutical mode of understanding. Journal of Phenomenological Psychology. 14 (2), 171-196.

LeCompte, M.D. \& Preissle, J. (1993). Ethnography and qualitative design in educational research (2nd edition). New York: Academic Press.

Leedy, P.D. (1997) Practical research. Planning and design. New Jersey: Von Hoffman.

Manoleas, P. \& Carrillo, E. (1991). A culturally syntonic approach to the field education of Latino students. Journal of Social Work Education, (27), 135-143.

Marshall, C. \& Rossman, G.B. (1995). Designing qualitative research. Beverly Hills CA: Sage.
Merriam, S.B. (1991). Case study research in education - a qualitative approach. Oxford: Jossey-Bass.

Miller, D. (1997). Mentoring structures: Building a protective community. Preventing School Failure, 41 (3), 105-109.

Mouton, J. (1996). Understanding social research. Pretoria: Van Schaik.

Mouton, J. \& Marais, H.C. (1990). Metodologie van die geesteswetenskappe: Basiese begrippe. Pretoria: RGN.

Omery, A. (1983). Phenomenology: A method for nursing research. Advances in nursing science, 5 (2), 49-63.

Patton, M.Q. (1990). Qualitative evaluation and research methods (2nd ed.). Beverly Hills CA: Sage.

Rockwell, S. (1997). Mentoring through accessible, authentic opportunities. Preventing School Failure, 41 (3), 111-114.

Rossouw, G.J. (1994): Business ethics. A Southern African perspective. Halfway House: Southern.

Rossouw, G.J. (2002). Business ethics in Africa (3rd ed.). Cape Town: Oxford University Press.

Rossouw, G.J. \& Van Vuuren, L.J. (2003). Business ethics as a strategic imperative for organisations: The business case for business ethics. Management Dynamics, 12 (1), 2-11.

Rossouw, G.J. \& van Vuuren, L.J. (2004). Business ethics (3rd ed.). Cape Town: Oxford University Press.

Schurink, W.J. (1988). The methodology of unstructured interviewing. (in Mouton, J. Introduction to research. Module 3). Pretoria: HSRC.

Skiffington, S. \& Zeus, P. (2002). The complete guide to coaching at work. New York: McGraw-Hill.

Townsel, K.T. (1997). Mentoring African American youth. Preventing School Failure, 41 (3), 125-127.

Van Vuuren, L.J. (2002). Institutionalising business ethics: A multi-level strategy. Management Dynamics, 11 (2).

Wickman, F. \& Sjodin, T. (1997). Mentoring. New York: McGraw-Hill.

Wolcott, H.F. (1994). Transforming qualitative data. Beverley Hills, CA: Sage.

Young, T. (2003) www.etrainingcenter.org.

Zunz, S.J. (1991). Gender-related issues in the career development of social work managers. Affillia, 6 (4), 39-52. 
Prof C Bester

Dr J Bosman

Prof J Buitendach

Dr M Coetzee

Prof JJ de Beer

Ms E du Toit

Dr LTB Jackson

Dr C Jonker

Mr M Meyer

Mr A Moerdyk

Dr C Pietersen

Prof AMG Schreuder
University of the Free State

North West University

North West University

UNISA

University of Pretoria

North West University

North West University

North West University

UNISA

Rhodes University

University of Limpopo

UNISA 